\title{
COMO O FILME UMA PROVA DE AMOR LIDA COM A QUESTÃO DO "IRMÃO SALVADOR" (E O QUE PODEMOS APRENDER COM ELE)
}

\section{HOW THE FILME MY SISTER'S KEEPER DEALS WITH THE QUESTION OF THE "SAVIOR SIBLINGS" (AND WHAT WE CAN LEARN FROM IT)}

\author{
${ }^{1}$ Ana Letícia Valladão Giansante \\ ${ }^{2}$ Sérgio Nojiri
}

\section{RESUMO}

O presente artigo tem como finalidade, a partir da relação entre Cinema e Direito, apresentar uma discussão sobre a ideia de "irmão salvador". Para tanto, utilizou-se o filme Uma Prova de Amor, o qual aborda uma problemática real e contemporânea que carece de atenção por parte de estudiosos do Direito. O filme narra fatos que podem ser interpretados como violações à dignidade da pessoa humana e a direitos de personalidade. Desta forma, objetiva-se uma reflexão crítica sobre o tema, à luz da promoção e efetivação de preceitos constitucionalmente assegurados.

Palavras chaves: Uma Prova de Amor; Irmão Salvador; Dignidade Humana; Direitos de Personalidade.

\begin{abstract}
This article intends to present a discussion about the idea of "Savior Sibling", from the perspective of the relationship between Cinema and Law. To do so, it used the movie "My Sister's Keeper," which deals with a real and contemporary problem that requires further attention by students of Law. The movie reports facts that may be interpreted as violations of human dignity and personality rights. In this way, it provides a critical reflexion on the subject, in light of the promotion and establishment of constitutionally assured precepts.
\end{abstract}

Keywords: My Sister's Keeper, Savior Sibling, Human Dignity, Personality Rights.

\footnotetext{
${ }^{1}$ Mestranda em Desenvolvimento no Estado Democrático de Direito pela Faculdade de Direito de Ribeirão Preto da Universidade de São Paulo - FDRP/USP, São Paulo (Brasil).

E-mail: algiansante@gmail.com

2 Doutor em Direito pela Pontifícia Universidade Católica - PUC, São Paulo (Brasil). Professor de Graduação e Pós-Graduação pela Faculdade de Direito de Ribeirão Preto da Universidade de São Paulo - FDRP/USP, São Paulo (Brasil). E-mail: nojiri@usp.br
} 


\section{INTRODUÇÃO}

O principal objetivo do presente ensaio é a apresentação de uma reflexão crítica, a partir de uma abordagem interdisciplinar entre o Cinema e o Direito, a respeito dos reflexos da problemática do "irmão salvador" nos direitos da personalidade, tendo em vista a falta de regulamentação específica deste assunto no ordenamento pátrio. Parte-se da premissa de que a sociedade contemporânea, marcada pela intensa mutabilidade, demanda de novas reflexões e soluções jurídicas e sociais.

A pesquisa foi realizada a partir do emprego de uma metodologia interdisciplinar, buscando através da interface entre direito e arte - especificamente o cinema -, novas perspectivas para o debate e para os problemas emergentes no mundo jurídico. Assim, usa-se o cinema como um meio de representar uma realidade concreta e trazer à discussão o tema em comento.

A análise do tema foi realizada mediante um estudo do ordenamento jurídico britânico. A adoção de um método de Direito Comparado apontou especificidades sobre o assunto em discussão que demandaram uma reflexão crítica e comparativa com o nosso sistema de direitos.

Assim, a partir problemática apresentada no filme Uma Prova de Amor (My Sister's Keeper), que aborda o desenvolvimento de técnicas de reprodução assistida e de diagnóstico pré-implantacional, pretende-se analisar as questões inerentes à ideia de "irmão salvador", especificamente no que tange aos direitos de personalidade, decorrentes da dignidade humana, que consiste em fundamento da República Federativa do Brasil.

No desenvolvimento do presente artigo, será apresentando um resumo do filme, bem como uma abordagem do conceito de irmão salvador e da realidade em que se insere, por meio de pontuações de direito comparado, para, por fim, analisar o cenário em face dos direitos de personalidade, contrapondo-se argumentos favoráveis e contrários.

Este ensaio visa, portanto, evidenciar a problemática inerente ao assunto, que já é uma realidade em diversos países. Busca-se a partir da concepção de "irmão salvador" relacioná-la com a exigência de garantia de direitos fundamentais assegurados pela Constituição Federal.

\section{O FILME}

Uma prova de amor (My Sister's Keeper) é um filme dirigido por Nick Cassavetes, que por sua vez foi baseado no livro homônimo de Jodi Picoult. No filme, a atriz Cameron Diaz 
interpreta uma mãe, Sara Fitzgerald, cuja filha adolescente Kate (Sofia Vassilieva) tem leucemia, e cuja filha mais jovem Anna, interpretada por Abigail Breslin, vive um conflito interno por ela ter sido concebida para ser uma doadora para sua irmã doente.

Antes de Sara saber que a filha possuía câncer, ela era uma advogada bem sucedida. Depois disso, passou anos de sua vida dedicando-se a Sara, em tempo integral, e buscando uma forma de combater a rara doença de sua filha. Após consultas com médicos e desgastantes procedimentos de quimioterapia, Sara e seu marido Brian (Jason Patrick) foram informados sobre a possibilidade de um tratamento pouco ortodoxo: ter um bebê doador.

Considerando que nenhum parente era um doador de medula óssea compatível com Kate, Sara e Brian tomam uma medida drástica de engenharia genética em busca do doador perfeito. O resultado? Anna.

Apesar de o filme trabalhar alguns assuntos que vão ocorrendo paralelamente à trama principal, como do irmão Jesse (Evan Ellingson) que era disléxico e ninguém da família parecia se importar, e do namoro de Kate com um rapaz que conheceu no hospital, também paciente de câncer, o foco se concentra na batalha legal iniciada por Anna.

À certa altura do filme Anna mostra-se relutante em continuar a ser uma mera doadora de órgãos, uma simples "irmã salvadora”. Assim, ela resolve contratar um advogado conhecido por seus comerciais na TV e aparentemente de bom coração (uma vez que Anna possui apenas um punhado de dólares). O advogado Campbell Alexander, interpretado por Alec Baldwin, irá se confrontar com a mãe de Anna que, como vimos, já foi uma competente advogada, perante uma corte presidida pela Juíza De Salvo (Joan Cusack), que, por sua vez, havia perdido recentemente sua filha.

O ponto alto do filme é quando Kate, aos 17 anos, fica com insuficiência renal e necessita que sua irmã menor Anna, de 13 anos, seja forçada pelos pais a doar um de seus rins. Anna argumenta que não poderá ser capaz de viver uma vida normal, já que não será capaz de praticar inúmeros esportes, beber álcool ou ser mãe no futuro.

Aparentemente são por essas razões que Anna processa seus pais por "emancipação médica" e direito sobre seu próprio corpo.

Toda essa situação causa fortes conflitos familiares. Enquanto o pai consegue enxergar o ponto de vista de Anna, a determinada mãe parece estar absolutamente convicta de que todos os esforços necessários para manter Kate viva se justificam, inclusive submeter Anna a dolorosos sacrifícios. 
No decorrer do filme é mostrada a relação fraternal próxima entre Kate e Anna, mas quando a última se recusa a doar um rim, isso significaria uma dolorosa ruptura entre ela e sua irmã? A resposta a esta pergunta implicaria um indesejado spoiler para quem ainda não assistiu ao filme ou leu o livro. Nesse sentido, é necessário sublinhar que o objetivo deste trabalho é trazer para a realidade jurídica algo que já está sendo objeto de observação e reflexão crítica por parte da literatura e do cinema de uma maneira que o direito muitas vezes não consegue.

De toda sorte, iremos, a partir da premissa lançada pela literatura e o cinema, buscar uma aproximação dessas abordagens com perspectivas próprias do direito.

\section{O CONCEITO DE IRMÃO SALVADOR}

Irmão salvador pode ser sucintamente definido como aquele que é concebido para fornecer material genético transplantável necessário a outro irmão. Em alguns casos, as células estaminais são recuperadas através do recolhimento placentar ou do sangue do cordão umbilical e são injetadas no irmão que possui a moléstia, na esperança de cura. Em outros, a doação de sangue, de medula óssea e de órgãos, são as opções de tratamentos que podem ser necessárias (HAYRI, p. 99, 2010).

Para Alexander Scguster o cenário é caracterizado pelo desenvolvimento das recentes técnicas de diagnóstico pré-implantacional que permitem, entre outras coisas, selecionar um embrião que possa dar vida a um indivíduo que possua características genéticas compatíveis com aquelas de um terceiro indivíduo, no caso, um irmão. Ressalta-se que a hipótese do irmão salvador também é conhecida por "bebês medicamentos” (SCGUSTER, p. 1416, 2011).

A atualidade do tema pode ser vista, por exemplo, em uma notícia do Jornal de Milão, de 2009, onde 378 crianças foram concebidas pelos genitores, na Lombardia, para curar outro filho do casal acometido de talassemia ou leucemia ${ }^{3}$.

Já foram também verificadas em outros países como nos Estados Unidos ${ }^{4}$, Espanha ${ }^{5}$ e, inclusive, no Brasil ${ }^{6}$, aplicações dessas técnicas para a seleção de embriões compatíveis. No

\footnotetext{
${ }^{3}$ Disponível em:

http://www.trapianti.salute.gov.it/imgs/C 17 rassegnaStampaCNT 457 Paragrafo_itemName 2 file.pdf. Acesso em: 17 nov. 2015.

4 Disponível em: http://ricerca.repubblica.it/repubblica/archivio/repubblica/1991/06/05/arrivano-bambinidonatori-nati-solo-per.html. Acesso em: 08 nov. 2015.

${ }^{5}$ Disponível em: http://www.uaar.it/news/2008/10/14/spagna-nasce-primo-bimbo-selezionato-per-curare-fratello. Acesso em: 08 nov. 2015.

${ }^{6}$ Disponivel em: http://saude.estadao.com.br/noticias/geral,nasce-no-brasil-1-bebe-selecionado-geneticamentepara-curar-irma,835877. Acesso em: 10 nov. 2015.
} 
Reino Unido, por exemplo, existe um órgão específico para questões conexas ao uso dessas técnicas, chamado Human Fertilisation and Embryology Authority (HFEA), que dá autorização para que a criação e utilização do embrião sejam consideradas legais. Este órgão já autorizou o emprego de técnicas de diagnóstico pré-implantacional para que uma criança fosse doadora de tecido para um irmão que tinha necessidade de um transplante de medula óssea (McLEAN, p. 391, 2006).

A polêmica sobre o tema centra-se na discussão da utilização de embriões e, portanto, de futuros seres humanos pelo valor ou utilidade que teriam a outra pessoa e não pelo valor intrínseco de cada pessoa (FREEMAN, p. 391, 2006).

Tudo isso se liga diretamente aos direitos de personalidade dos irmãos salvadores, como o seu bem-estar e legítimo interesse (FREEMAN, p. 391, 2006). Segundo Freeman, devese levar em consideração se esta escolha é um exercício da autonomia que gera danos ou abusos à criança a ser concebida. Não se deve ignorar a dignidade do irmão salvador. A questão principal, portanto, é a seguinte: para promover o bem estar do irmão doente (que já existe) os interesses do irmão salvador podem, de alguma maneira, ser comprometidos (FREEMAN, p. 398, 2006)?

\section{O CASO DO REINO UNIDO}

No Reino Unido existe um órgão específico para a análise de situações que envolvem embriões, o Human Fertilisation and Embryology Authority (HFEA) além de uma legislação, o Ato $H F E$, de 1990, que embora não limite o acesso de tratamentos para fertilidade, limita o fornecimento de tais tratamentos, colocando o bem-estar da criança como condição para a obtenção da licença.

Dessa forma, não há previsões específicas sobre "pre-implantation tissue typing" (PTT), que permite a escolha de irmãos salvadores. A HFEA, em resposta aos requerimentos de licença, desenvolveu uma política própria em matéria de PTT. Este órgão permitu o uso dessas técnicas para escolher um embrião compatível para salvar a vida de uma criança já concebida, Zain Hashmi, acometida de beta talassemia maior. De outro lado, não permitiu o uso das mesmas técnicas no caso Whitaker, de uma criança portadora de Anemia de DiamondBlackfan.

$\mathrm{O}$ argumento utilizado pela $H F E A$ para diferenciar estes dois casos é que no primeiro a doença era genética, de tal modo que o uso das técnicas de diagnóstico pré-implantacional e 
de tissue typing seriam capazes de permitir que o irmão salvador não nascesse com a doença. No segundo, todavia, a doença não era genética e, por isso, o uso dessas técnicas não era capaz de fornercer qualquer bem à criança a ser concebida, além do risco físico da biopsia e do risco psiquíco de ser concebido com o fim de salvar um irmão (TAYLOR-SANDS, 2010). O uso das PTT só é possível, portanto, com a utilização concomitante da técnica de diagnóstico genético pré-implantacional (PGD) que permite a escolha de embriões livres da doença genética.

Todavia, diversas pessoas sustentaram que, ainda que efetuado isoladamente ou em combinação com técnicas de PGD, os riscos e benefícios para a criança que nascerá em consequência do uso das PTT continuam. Isto porque o uso das técnicas de diagnóstico préimplantacional não conferem nenhum benefício curativo ou regenerativo direto ao embrião. Por este motivo, a HFEA mudou sua política no ano de 2004, de tal forma que isoladamente ou em combinação com PGD, foi permitido o uso da PTT para selecionar embriões compatíveis com o irmão acometido da moléstia. A nova política declarou que a PTT deve ser disponível apenas com o escopo de criar um irmão compatível para a doação nos casos em que existe uma necessidade real de salvar uma vida. Todavia, a permissão depende da análise de cada caso.

A atual política da HFEA sobre PTT está contida na nota de orientação 10 de seu Código de Comportamento. Ela requer que os centros levem em consideração as circunstâncias de cada caso, bem como as condições do irmão existente, as possíveis consequência para cada criança que possa nascer em consequência de PTT e as circunstâncias familiares em busca do tratamento ${ }^{7}$.

Essa mesma política requer também informações detalhadas sobre o procedimento, os riscos conexos, a probabilidade de sucesso, o provável impacto sobre os membros da família e outras formas de tratamento, àqueles que pensam em usar a PTT. Por fim, exige que os centros que oferecem essas técnicas possuam uma estrutura para facilitar, a longo prazo, o estudo das consequências médicas e psicossociais das crianças nascidas em consequência da PTT.

\section{DIREITOS DA PERSONALIDADE}

De acordo com o acima exposto, a questão tem uma relação intrínseca com os direitos da personalidade e com o fato de que as pessoas devem ser vistas como um fim em si mesmo,

\footnotetext{
7 Disponível em: http://www.hfea.gov.uk/docs/Guidance_Note_10_-_Embryo_testing_and_sex_selection.pdf. Accesso a: 16 dec. 2015.
} 
e não é apenas como uma subjetividade - um mero valor ontológico - mas também como uma estrutura de valores, um ser axiológico (PASQUINO, p. 551, 2011).

Assim, aqueles que são contra trazer uma criança ao mundo apenas para salvar outra criança acreditam que o irmão salvador será tratado como uma coisa, e não como uma pessoa, apenas um meio para curar o irmão doente (FREEMAN, p. 398, 2006).

Nesse mesmo sentido, há outra questão que merece nossa atenção por produzir reflexos na integridade física e psíquica do irmão salvador. Como vimos em passagens do filme Uma prova de amor e que foi um dos argumentos utilizados pelo advogado de Anna, os procedimentos médicos são fortemente invasivos, principalmente nos casos em que é necessário retirar a medula óssea, o sangue, e os órgãos para procurar uma cura.

Ainda assim, existem aqueles que não veêm nenhuma violação aos direitos de personalidade do irmão salvador, argumentando que este é concebido como qualquer outra criança, isto é, com o fim de amar e cuidar do mesmo modo que os genitores amam e cuidam a criança adoecida (FREEMAN, p. 398, 2006). Esta parte da doutrina sustenta, por exemplo, que nos casos em que as células estaminais utilizadas são do sangue do cordão umbilical, não haverá nem mesmo intrusões físicas sobre a criança. Além disso, partem da estranha premissa que a alternativa a ser um irmão salvador seria a não existência e, assim, questionam se isso seria preferível (HAYRI, 2010).

A questão, portanto, é de saber se a busca de uma cura para o primeiro filho pode justificar uma violação à integridade física ou mental, à privacidade, à falta de consentimento, etc. Em suma, onde fica, nesta questão, a dignidade do irmão salvador?

\subsection{DIGNIDADE HUMANA}

A dignidade humana é prevista na Constituição Federal como um dos fundamentos da República Federativa do Brasil, sendo um direito do qual qualquer ser humano é portador. Além disso, é considerado um princípio base de diversos ordenamentos jurídicos, ainda que não expressamente previsto. A dignidade humana é tida como um príncipio-valor e mostra a necessidade da sua concretização nos novos cenários que se apresentam (PASQUINO, p. 548, 2011).

A base da discussão é, assim, o papel central que a pessoa humana ocupa nos ordenamentos jurídicos vigentes, segundo o princípio da dignidade da pessoa humana. Este princípio tem uma relação com o conceito concreto de pessoa, direcionado não a uma qualidade 
(capacidade de direito), mas sim ao próprio sujeito na totalidade de seus elementos constitutivos e, portanto, na sua dimensão vital (DONEDA, 2002).

Nesse sentido, Habermas questiona o uso de técnicas de diagnóstico préimplantacional com a finalidade de conceber uma criança para salvar o irmão. Segundo ele, é de se pensar se a dignidade humana é compatível com a seleção de um embrião por meio de um exame genético (Apud CARDIN \& MAIA).

Além disso, quando se fala de técnicas de diagnóstico genético pré-implantacional, a noção de dignidade humana é fundamental e deve ser considerada em seus aspectos da realidade existencial e ontológica. Neste sentido, mesmo nos casos em que estas técnicas ajudem a promover a sobrevivência de uma vida humana, como seria o caso da concepção do irmão salvador, é fundamental manter a liberdade de se fazerem escolhas.

Assim, afirma-se que a dignidade humana é conservada apenas nos casos em que é acolhida a autonomia e o consenso do irmão salvador. Todavia, há casos, como o dos neonatos, em que indivíduos não possuem capacidade para expressar o seu consentimento. Uma possível solução seria a busca de um consenso entre os genitores, mas como vimos no filme Uma prova de amor, isso nem sempre é tão simples. Ademais, como também foi retratado na película, é possível que um ou ambos genitores estejam tão emocionalmente afetados pela doença de seu filho que colocam o seu bem-estar acima dos interesses e do bem-estar do irmão salvador (PLESSIS, 2001).

De outra parte, existem aqueles que dizem que a dignidade humana é um conceito tão indeterminado que não fica claro por qual motivo a proteção de uma noção tão vaga deva prevalecer sobre a vida de uma criança (SPRIGGS, p. 342).

\subsection{A INTEGRIDADE FÍSICA E PSÍQUICA}

A proteção à integridade física e psíquica no ordenamento pátrio pode ser vista como um desdobramento da dignidade humana, existindo previsão especifica de tutela da integridade física no Código Civil, em seus artigos 13, 14 e 15, os quais garantem não apenas os direitos sobre o próprio corpo, mas também a inviolabilidade deste (DINIZ, 2010, p. 130). Ademais, a tutela da integridade física e do equilíbrio psíquico é inerente ao direito á saúde, o qual deve ser garantido e efetivado pelo poder público, conforme preconiza o artigo 196, do Texto Maior.

Diante disto, questões atinentes ao dano à integridade física e mental do irmão salvador são, sem sombra de dúvida, um dos pontos centrais da problemática que estamos a analisar. Os 
riscos físicos decorrentes do procedimento de interfência embrional, além dos riscos psicológicos advindos das circunstâncias da concepção (descobrir que foi trazido ao mundo como fonte de reserva para outra pessoa) podem se tornar devastadores.

A utilização de ténicas de reprodução assistida e de biopsia embrional durante o procedimento de diagnóstico pré-implantacional cria inegáveis riscos de dano físico. Da mesma forma, técnicas invasivas de transfusão ou transplante, também criam riscos físicos e psicológicos. Sobre este ponto, há pesquisas indicando que crianças concebidas com o uso das técnicas de reprodução assistida têm maior probabilidade de nascerem mortas ou de morrerem logo após o nascimento, além de mostrarem uma maior predispoição a algumas doenças (TAYLOR-SANDS, p. 44, 2010).

Além disso, as intervenções médicas realizadas no embrião, para assegurar que ele nasça sem doenças, não visam o seu interesse, mas a sua compatibilidade com o irmão doente que já existe. Isso sugnifica que, em última instância, a proteção de interesses é voltada exclusivamente para o irmão doente e não para aquele que suporta os riscos do uso destas técnicas.

Há quem afirme, no entanto, que quando a criança nascer, ela não sofrerá dor, já que o procedimento de retirada das células estaminais do cordão umbilical não é um procedimento invasivo e, portanto, não haveria lesão à criança. (FREEMAN, p. 402, 2006).

Todavia, nos casos em que existe a necessidade de uma transfusão ou transplante, existem outros problemas correlacionados à integridade física de doadores de células estaminais, como a dor e o cansaço, além dos riscos da anestesia geral, usada para o transplante da medula óssea (TAYLOR-SANDS, p. 47, 2010).

Sobre os aspectos psicológicos, dois pontos merecem ser lembrados. O primeiro diz respeito ao momento em que a criança descobrir que foi concebida somente para ajudar o irmão a sobreviver. Ademais, questiona-se o risco desta mesma criança ser rejeitada após ela atingir (ou não) o seu escopo de salvar o irmão. Já os defensores argumentam que seria mais provável crer que o irmão salvador se sentisse orgulhoso e satisfeito por saber que foi responsável por salvar a vida de seu irmão e que isso estaria de acordo com o melhor interesse da criança (FREEMAN, p. 402-403, 2006).

Ainda sobre os riscos de danos à integridade psicológica, é necessário considerar as pressões criadas pelas expectativas dos pais. Essas pressões certamente refletirão na qualidade de vida do irmão salvador. Isso pode criar a tensões na autoimagem da criança (devo ser aquilo que sou o aquilo que meus pais desejam?). Em alguns cenários isso pode levar a quadros de 
ansiedade e depressão (HAYRI, p. 106, 2010). Neste sentido, um recente estudo mostrou que os irmãos doadores, que possuem como papel principal "salvar" a vida do irmão correm o risco de adquirir sentimentos de inferioridade, bem como de exclusão e de isolamento da família. Como narra a pesquisa, psicólogos pediram às crianças que fizessem um desenho da própria família e uma das crianças não se incluiu no próprio desenho (MILLS, p. 31, 2013).

Este mesmo estudo mostrou que a ansiedade, o estresse e o temor sobre o que pode acontecer se o tratamento for abandonado são, nesses casos, sintomas comuns. Verificou-se, também, a existência do sentimento de não possuir qualquer controle sobre o próprio corpo. Mas talvez o dado mais relevante é o que apontou que para alguns, submetidos ao procedimento de doação, a possibilidade de salvar a vida do irmão não compensou o sofrimento causado (MILLS, p. 31, 2013).

\subsection{AUTONOMIA INDIVIDUAL}

Tal direito traz reflexos no âmbito da autodeterminação e da liberdade de escolha, recebendo status constitucional, embora não previsto expressamente, podendo ser visto como uma decorrência da cláusula geral de liberdade e das normas jurídicas que visam resguardar os projetos de vida dos indivíduos (NETO, p. 351-352, 2014).

Em outro sentido, existem aqueles que trazem a dignidade humana como autonomia, no sentido de que a promoção de uma vida digna pressupõe, invariavelmente, o respeito à autonomia do indivíduo e de que a dignidade humana abarca uma dimensão de empoderamento, de forma a garantir aos indivíduos as condições necessárias de decisão e ação para alcacenrem seus objetivos existencias (NETO, p. 353, 2014).

Assim, nota-se que é em decorrência deste direito que, no âmbito das relações médicas, existe o princípio do consentimento informado, de forma que o respeito à autonomia e à autodeterminação é pressuposto para que seja considerada lícita a manifestação da vontade do paciente em se submeter a um tratamento perigoso ou doloroso.

Diante disto, no caso de irmão salvador há um evidente problema. A decisão sobre a doação é feita pelos genitores, representantes legais da criança (LENTI, p. 417, 2011). Nesses casos, a criança não possui condições de se exprimir, já que a necessidade de assistência genética é automática, de tal modo que a doação é essencialmente compulsória. Assim, o irmão salvador pode ser constrangido, por sua família ou por seus representantes legais, a se submeter a um processo de doação, através do procedimento de transfusão, transplante de medula óssea 
e também de doação de órgãos. Nesses casos, a autorização fornecida pelos genitores não pode ser vista do mesmo modo que o consentimento informado, considerada a situação da criança que foi concebida especialmente para ser submetida a tais procedimentos.

A Constitução Federal, como já exposto, trata a saúde como um direito social fundamental de todos os indivíduos e o reconhecimento da autonomia e da autodeterminação impõe o consentimento livre e informado para a realização de intervenções médicas e biológicas.

A questão, portanto, é se a criança que ainda não tem a plena capacidade de fornecer o seu consentimento, pode ser constrangida a se submeter a procedimentos invasivos com a simples permissão dos seus genitores.

Mesmo que a criança já consiga exprimir sua vontade, permanece a questão de saber se este consentimento é verdadeiramente uma reflexão honesta de sentimentos ou um reflexo de um sentimento de dever, já que a doação é a razão da concepção do irmão salvador. Não se pode menosprezar, ainda, eventuais pressões, conscientes ou inconscientementes, a que o doador possa ser submetido pela família.

Neste sentido, o transplante feito com crianças menores e incapazes, que ainda não possuem a maturidade para compreender as consequências deste ato, realizado apenas com o consetimento dos genitores, pode ser interpretado como uma aberração jurídica. O fato de uma criança não ser capaz de avaliar a complexidade da situação não pode ser motivo para que os seus genitores diponham livremente sobre o seu corpo (RAMOS, p. 16), já que negar a autonomia das crianças mostra claramente que o seu status como indivíduo independente é ignorado e que ela ainda é tratada como uma mera propriedade dos genitores (PLESSIS, p. 69, 2011).

\subsection{PRIVACIDADE DOS DADOS GENÉTICOS}

A privacidade pode ser definida como o direito de manter o controle sobre as próprias informações; e, de forma mais geral, se apresenta como uma dimensão da própria liberdade existencial, constitutiva não apenas da esfera privada, mas também da pública (RODOTA, 2010).

A doutrina pátria classifica o direito à privacidade como gênero do qual o direito à intimidade, à vida privada, à honra e à imagem são espécies. Assim, o direito à privacidade 
abarcaria todos os direitos fundamentais assegurados pelo art. $5^{\circ}$, inciso $\mathrm{X}$, do Texto Maior (ECHETERHOFF, p. 124, 2007).

A privacidade é, portanto, um princípio que garante a tutela das informações (FUCCI, 2002), dos dados pessoais, os quais, em diversos ordenamentos, possuem uma tutela específica, a fim de garantir os direitos fundamentais correlatos. Dentre esses dados pessoais existem os dados genéticos, que são quaisquer dados que dizem respeito às características hereditárias de um indivíduo.

Especificamente no que tange à natureza dos dados genéticos, nota-se que a doutrina o trata como dados sensíveis ou, até mesmo, como dados super-sensíveis, tendo em vista as consequências que a sua difusão podem gerar para o indivíduo, o que impõe, por conseguinte, a necessidade de um dever especial de cuidado e de garantias reforçadas de proteção (ECHETERHOFF, p. 151, 2007).

Neste sentido, a seleção do embrião geneticamente compatível com o irmão adoecido poderia adentrar a privacidade da esfera genética, já que este procedimento pressupõe a análise de todo o perfil genético, que constitui a própria essência do indivíduo, sua identidade mais profunda, além de permitir traçar a sua história presente e futura (LELLA, p. 508, 2009).

Outras questões relacionadas também já foram levantadas, como a falta de consentimento sobre como tecido descartado do doador vai ser utilizado, e informações sobre um potencial doador: a) a respeito de sua compatibilidade com o destinatário, e b) de que não possui a doença do destinatário (HAYRY, p. 109, 2010).

A questão principal, no entanto, persiste: a possibilidade de salvar um irmão seria um bom motivo para justificar uma imersão nos dados genéticos da criança a ser concebida?

\subsection{O MELHOR INTERESSE DA CRIANÇA}

O Princípio do Melhor Interesse da Criança está previsto na Constituição Federal, em seu artigo 227, caput, o qual consagrou o princípio da prioridade absoluta dos direitos da criança, bem como no Estatuto da Criança e do Adolescente, em seus artigos $4^{\circ}$, caput, e $5^{\circ}$.

Diante disto, no caso do irmão salvador, no qual a vontade da criança não pode ser aferida de forma segura e em que o consentimento dos genitores é evidentemente suspeito, há que se realizar um sopesamento de interesses das crianças (PLESSIS, P. 71, 2011).

A questão gira em torno de eventual ausência de autonomia do irmão salvador e o consentimento dos genitores. Neste caso, no que diz respeito à submissão ao procedimento de 
doação, os pais seriam capazes de decidir de acordo com o melhor interesse do irmão salvador? Como intérpretes privilegiados, já que devem, em tese, tomar a melhor decisão no interesse dos filhos (LENTI, p. 427, 2011), os pais poderiam optar pela realização dos melhores interesses do outro filho?

Há quem afirme que o melhor interesse da criança é tornar-se um irmão salvador, já que seria possível ajudar seu irmão e também tornar os genitores mais felizes (HAYRI, p. 105, 2010). De acordo com essa visão, existe uma relação entre os interesses sociais, emocionais e psicológicos de uma pessoa com a felicidade da sua família e, por essa razão, a alternativa à doação, que seria deixar o irmão morrer, desenvolveria na família um desagradável sentimento marcado pela morte de um de seus membros. Além disso, afirma-se que o bem-estar dos outros é parte do bem-estar da própria pessoa que ajuda (PENNINGS, 2002). Desse ponto de vista, a doação seria no melhor interesse da criança.

A situação, no entanto, não é tão simples assim. Só para mencionar algumas possíveis complicações, podem haver riscos na biopsia embrional e no processo de doação, além da real possibilidade de o procedimento não curar a doença do irmão (HAYRI, p. 102, 2010).

Assim, tratar do melhor interesse do irmão salvador significa considerar que ele não deverá sofrer danos físicos, psicológicos ou sociais (TAYLOS-SANDS, 2010).

\section{CONSIDERAÇÕES FINAIS}

As técnicas de reprodução humana assistida não são utilizadas apenas por casais com problemas de infertilidade, mas, como vimos, são também usadas nos casos dos irmãos salvadores (doadores), o que é permitido por meio do uso das técnicas de diagnóstico préimplantacional. Diante deste cenário, algumas questões foram aqui analisadas.

Uma delas diz respeito ao papel central do ser humano nos diversos ordenamentos jurídicos, representado, sobretudo, por meio do princípio da dignidade humana. Este princípio redimensiona outros direitos fundamentais anteriormente reconhecidos (RODOTA, 2010), como a liberdade, a igualdade, etc., e também inspira os diversos direitos de personalidade, tais como a integridade física e mental, a autonomia, a privacidade e o melhor interesse da criança.

A questão crucial, no entanto, tem a ver com a quantidade de sofrimento a que uma pessoa deve se submeter para aliviar o sofrimento de outra, isto é, em que medida é possível conceber uma criança apenas para salvar um irmão adoecido, já que existem riscos conhecidos (e outros desconhecidos) correlatos a estes procedimentos. 
Quem argumenta a favor da concepção de irmãos salvadores afirma que a não concepção é o mesmo que a não existência; que ajudar um irmão seria motivo de orgulho; que não se pode falar em danos à integridade física e mental, já que existem outras crianças (não concebidas para tal fim) que são sumetidas a transfusões, transplantes ou doações, etc.

A fragilidade desses argumentos é evidente. Afinal, a concepção de uma criança não utilizada como um mero instrumento para o bem estar de outra não seria, por si só, motivo de orgulho? Nada obstante, resta ainda a situação de se submeter uma criança a uma diversidade de procedimentos, muitos deles dolorosos, sem o seu consentimento, que seria substituído pelo consentimento dos genitores.

No filme Uma prova de amor esses conflitos são mostrados de uma forma que dificilmente um texto jurídico faria. Apesar de o filme ser inspirado em um romance, escrito por Jodi Picoult, ele traz uma versão muito mais próxima da realidade que os textos acadêmicos. Nele, a mãe, Sara, está tão obcecado em salvar sua filha doente Kate que, além de não perceber os problemas de seu filho mais velho Jesse, trata a filha mais nova, Anna, como uma solução de bio-engenharia para a doença de Kate.

Encarar a questão do irmão salvador deste ponto de vista ajuda-nos a compreender de uma maneira mais humana os problemas que uma família realmente atravessa. Quando Anna, uma criança de apenas 11 anos de idade, é requisitada para ser doadora de um rim e contrata um advogado para a obtenção de uma "emancipação médica" percebemos o peso de um processo judicial no núcleo familiar, especialmente quando há conflitos de interesses entre pais e filhos. E este tipo de conflito dificilmente seria retratado por artigos de revistas jurídicas especializadas redigidos em linguagem técnica (em "juridiquês").

Ao final, percebemos que todo o cenário, marcado por intervenções no embrião e no corpo capazes de gerar danos físicos, e que fazem de uma criança um irmão salvador, na realidade, envolve, antes de tudo, uma questão ética. Quando Anna, mediante seu advogado, pede ao juízo emancipação, ela está requerendo nada mais que a dignidade já antevista por Kant há muito tempo atrás, de ser considerada como um fim e não como um meio, ou seja, como um valor absoluto e não relativo.

Mas é a linguagem cinematográfica que torna tudo mais interessante. Apesar de a doença de Kate ser o centro das atenções de toda a família e fazer com que a mãe, Sara, se confronte em juízo com sua filha Anna, o filme deixa claro que ainda persiste em Sara um sentimento de amor em relação à Anna, apesar de seu desejo de torná-la uma filha salvadora. 


\section{BIBLIOGRAFIA}

CARDIN, Valéria Silva Galdino; GUERRA, Marcela Gorete Rosa Maia. Do diagnóstico genético pré-implantacional para a seleção de embriões com fins terapêuticos: uma análise do bebê-medicamento. Disponível em: file://C:/Users/Ana\%20Leticia/Downloads/0.67923500_1443182583_uma_analise_d0_bebemedicament0\%20(1).pdf. Acesso em: 13 jan. 2016.

DINIZ, Maria Helena. Curso de direito civil brasileiro. 26 ed. São Paulo: Saraiva, 2010. ECHTERHOFF, Gisele. $O$ direito à privacidade dos dados genéticos. $2007.213 \mathrm{f}$. Dissertação. Pontifícia Universidade Católica do Paraná: Curitiba, 2007.

DONEDA, Danilo. Os direitos da personalidade no código civil. In TEPEDINO, Gustavo (org.). A parte geral do novo Código Civil: Estudos na perspectiva civil-constitucional. Rio de Janeiro: Renovar, 2002.

FREEMAN, Michael. Savior Siblings. In McLEAN, Sheila A. M. First Do No Harm: Law,Ethics and Healthcare. Scotland: University of Glasgow, 2006. Disponível em: https://books.google.it/books?id=Uvd3xOMIXpkC\&pg=PA389\&hl=pt-

$\mathrm{BR} \&$ source $=\mathrm{gbs} \_$toc_r\&cad $=3 \# \mathrm{v}=$ onepage $\& \mathrm{q} \& \mathrm{f}=$ false. Acesso em: 17 nov. 2015.

FUCCI, Sergio. Privacy e dati genetici, 2002. Disponível em: http://www.privacy.it/ccasciafucci.html. Acesso em: 14 jan. 2016.

HAYRY, Matti. Rationality and the Genetic Challenge: Making People Better?. New York: Cambridge University Press, 2010, Disponível em: https://books.google.it/books?id=rmhsEShMufQC\&pg=PA100\&lpg=PA100\&dq=first+do+n o+harm+law+ethics+and+healthcare+saviour+siblings\&source=bl\&ots=DfGGSruYuQ\&sig= OaFSrJPzByu8zsVjkh2fZsEdKIE\&hl=ptBR\&sa=X\&ved=0CCkQ6AEwAmoVChMI_6rPtLS SyQIVRzoUCh3LUgdq\#v=onepage $\& q=$ first $\% 20 \mathrm{do} \% 20$ no $\% 20$ harm $\% 201 \mathrm{aw} \% 20 \mathrm{ethics} \% 20 \mathrm{a}$ nd\%20healthcare\%20saviour\%20siblings\&f=false. Acesso em: 09 dec. 2015.

LELLA, Francesa di. Ambiti di rilevanza e tutela dei dati genitici. In Diritto e Giurisprudenza: rassegna di dottrina e di giurisprudenza civile. Jovene - anno CXXIV SERIE III $\quad-\quad 2009 / 4 \quad$-Napoli. Disponível em: https://www.academia.edu/4329533/Ambiti_di_rilevanza_e_tutela_dei_dati_genetici. Acesso em: 14 jan. 2016.

LENTI, Leonardo. Autodeterminazione e consenso nell'incapacità e capacità non completa. In RODOTÀ, Stefano; ZATTI, Paolo. Tratatto de Biodiritto: I Diritti in Medicina. Milano: Giuffrè Editore, 2011.

MILLS, Janelle. Understanding the position of the savior sibling: How can we sabe lives and protect savior siblings? Winston-Salem, North Carolina, 2013.

NETO, Heráclito Mota Barreto. O princípio constitucional da autonomia individual. Boletim científico ESMPU, Brasília, a. 13 - n. 42-43, p. 331-366 - jan./dez. 2014. 
OLIVEIRA-CARDOSO, EA; SANTOS, MA; MATROPIETRO, AP; VOLTARELLI, JC. Doação de medula óssea na perspectiva de irmãos doadores. Rev. Latino-Am. Enfermagem. set-out 2010.

Disponivel em: http://www.scielo.br/scielo.php?pid=S010411692010000500011\&script=sci_arttext\&tlng=pt. Acesso em: 15 dec. 2015.

PASQUINO, Teresa. Dignità della Persona e Diritto del Malato. In RODOTÀ, Stefano; ZATTI, Paolo. Tratatto de Biodiritto: I Diritti in Medicina. Milano: Giuffrè Editore, 2011, p. 543-564.

PENNINGS, G; SCHOTS, R; LIEBAERS, I. Ethical considerations on preimplantations genetic diagnosis for HLA typing to match a future child as a donor of haematopoietic stem cells to a sibling, 2002. Disponível em: http://humrep.oxfordjournals.org/content/17/3/534.full\#ref-5. Acesso em: 14 jan. 2016.

PLESSIS, Emma Kate du. The constitutional rights of 'benefactor children' and 'saviour siblings' to bodily integrity and autonomy. Dissertation, Nelson Mandela Metropolitan Univesity, 2011. Disponível em: http://reference.sabinet.co.za/document/EJC155243. Acesso em: 10 dec. 2015.

RAMOS, Ana Vírginia Gabrich Fonseca Freire; MORAIS, Luísa Cristina de Carvalho. Os limites da luta para salvar um filho: questionamentos acerca dos savior siblings.

RODOTA, Stefano. Antropologia dell'homo dignus, 2010. Disponível em: http://civilistica.com/wp-content/uploads/2015/02/Rodot\%C3\%A0-civilistica.coma.2.n.1.2013.pdf. Acesso em: 12 jan. 2016.

\section{Trasparenza e democrazia. Disponível em:} http://cc.fondazionesancarlo.it/fondazione/Viewer?cmd=attivitadettaglio\&id=14. Acesso em: 16 jan. 2015.

SCGUSTER, Alexander. La procreazione selettiva. In RODOTÀ, Stefano; ZATTI, Paolo. Tratatto de Biodiritto: il governo del corpo. Tomo II. Milano: Giuffrè Editore, 2011, p. 1416.

SPRIGGS, M. Is conceiving a child to benefit another against the interests of the new child? J Med Ethics. Disponível em:

http://www.ncbi.nlm.nih.gov/pmc/articles/PMC1734160/pdf/v031p00341.pdf. Acesso em: 03 dec. 2015.

TAYLOR-SANDS, M. Creating saviour siblings: reconsidering the role of the welfare of the child principle in regulating pre-implantation tissue typing in Australia. $\mathrm{PhD}$ thesis, Melbourne Law School, The University of Melbourne, 2010, p. 153. Disponível em: http://hdl.handle.net/11343/36116. Acesso em: 15 dec. 2015.

TEPEDINO, Gustavo. Normas Constitucionais e Direito Civil. Disponível em: http://fdc.br/Arquivos/Mestrado/Revistas/Revista04e05/Docente/10.pdf. Acesso em: 10 nov. 2015 